\title{
La superación de los docentes para el tratamiento a la dimensión ambiental para el desarrollo sostenible, Cuba
}

Teachers Improvement for the environmental dimension treatment for sustainable development

\author{
Dianelys Rigo Prado ${ }^{1}$ \\ María del Carmen Hernández Valdés ${ }^{2}$ \\ Geisha Calero de la Paz ${ }^{3}$
}

\section{Resumen}

La superación continua y permanente de los docentes constituye una prioridad del Ministerio de Educación Superior, Cuba, toda vez que este debe estar a tono con los adelantos de la ciencia y la tecnología en cada momento histórico concreto. Es un estudio cualitativo del tipo investigación acción participativa, motivado por la necesidad de actualización constante de sus saberes acerca de la dimensión ambiental para su inclusión y salida en el proceso educativo; constituyendo una tarea de primer orden. A esa necesidad responde la presente investigación que tuvo como objetivo: reflexionar desde el punto de vista teórico acerca de la superación de los docentes en el tratamiento a la dimensión ambiental para el desarrollo sostenible.

Palabras clave: superación de los docentes; dimensión ambiental y desarrollo sostenible.

\section{Abstract}

The continuous and permanent improvement of teachers is a priority of the Ministry of Higher Education, Cuba, since it must be in tune with the advances of science and technology at each specific historical moment. It is a qualitative study of the participatory action research type, motivated by the need to constantly update its knowledge about the environmental dimension for its inclusion and exit in the educational process; constituting a task of the first order. This need responds to the present research which objective was to reflect from the theoretical point of view about the improvement of teachers in the treatment of the environmental dimension for sustainable development.

\footnotetext{
1 Licenciada en Educación Especialidad Instructora de Arte. Profesora Asistente y coordinadora de la Carrera Licenciatura en Gestión Sociocultural para el Desarrollo de la Universidad “José Martí Pérez” Sancti Spíritus. Correo: dianelys@uniss.edu.cu ORCID https// orcid.org/oooo-0oo2-4316-8593

2 Master en Ciencias de la Educación. Profesora de la Universidad “José Martí Pérez” Sancti Spíritus. Correo: mchernandez@uniss. edu.cu ORCID: https://orcid.org/oooo-0001-5232-0151

3 Doctora en Ciencias de la Educación. Profesora Titular de la Universidad de la Universidad “José Martí Pérez" Sancti Spíritus. Correo: geisha@uniss.edu.cu ORCID: https://orcid.org/oooo-0001-9240-638X
}

Recibido: 08/01/2021 - Aprobado: 05/02/2021 
Keywords: Teachers Improvement; Environmental Dimension and Sustainable Development.

\section{Introducción}

Hace más de 40 años en Estocolmo, Suecia, se tomaron acuerdos sobre la apremiante necesidad de abordar el problema del deterioro ambiental. En la Conferencia de las Naciones Unidas sobre el Medio Ambiente y el Desarrollo, celebrada en Río de Janeiro (1992) se convino en que la protección del medio ambiente, el desarrollo social y el desarrollo económico eran fundamentales para lograr el desarrollo sostenible basado en los principios de Río. Para alcanzar este objetivo se aprobó un programa de alcance mundial titulado Programa 21 y la Declaración de Río sobre el Medio Ambiente y el Desarrollo, a partir de lo cual la Educación Ambiental adquiere una nueva dimensión y adecuación temática y conceptual.

En el intervalo entre la Conferencia de Río (1992) y la de Johannesburgo (2002), las naciones del mundo se han reunido en varias conferencias bajo los auspicios de las Naciones Unidas para expresar sus opiniones en una búsqueda constructiva del camino común hacia un mundo en que se respete una amplia visión del futuro de la humanidad.

El término Educación Ambiental (EA), comienza a emplearse a finales del siglo XX y se establece en función de una "educación para el Medio Ambiente". Se considera como un modelo teórico, metodológico y práctico que trasciende el sistema educativo tradicional y alcanza la concepción de Medio Ambiente y desarrollo, se concibe como una educación para el desarrollo sostenible, que se expresa y se planifica a través de la introducción de la dimensión ambiental en los procesos educativos, estableciendo sus requerimientos en este.

La Ley 81 del Medio Ambiente (1997), establece que la EA es un instrumento de gestión para solucionar o mitigar las afectaciones ambientales, por lo que forma parte de las proyecciones y directrices de la Estrategia Ambiental Nacional devenida de esa Ley.

En la Estrategia Nacional de Educación Ambiental (en lo adelante, ENEA), se puntualiza que la introducción de la dimensión ambiental en la escuela, consiste en la incorporación de un sistema de conocimientos, habilidades, actitudes, aptitudes y valores, conscientemente y contextualizado, por medio de acciones pedagógicas que integran el trabajo alrededor del Medio Ambiente (CITMA, 1997).

En consecuencia, se elaboran los planes de estudio y los programas de las diferentes asignaturas mediante las cuales se puede contribuir a desarrollar la educación ambiental en las universidades, pero en el caso particular de los contenidos de gestión 


\section{EDUCACIÓN}

sociocultural, se abren extensas potencialidades para desarrollar un trabajo efectivo en tal dirección. Sin embargo, a pesar de que los programas de las especialidades que se imparten en la carrera Gestión Sociocultural para el Desarrollo en el país presentan enfoques y orientaciones de carácter ambientalista, este tipo de trabajo es susceptible de ser enriquecido de forma más objetiva, sistemática y contextualizada.

Si bien en las universidades se abordan temáticas relacionadas con el medio ambiente, no siempre se logra alcanzar una clara comprensión de las responsabilidades que en este sentido tiene la institución docente, por lo que un trabajo eficiente en esta dirección no constituye una práctica en el desempeño.

Fortalecer la educación ambiental a favor de conductas individuales y colectivas basadas en: una ética consecuente con el desarrollo sostenible, integrada a la praxis sociocultural cotidiana, constituye hoy la prioridad para la educación superior en Cuba.

No obstante, a que esta arista de su desempeño profesional, de alguna manera esté declarada en el Modelo del Profesional, son visibles las limitaciones en este sentido, determinándose dentro de las principales causas que lo condicionan: insuficiente tratamiento en el currículo base a la formación ambiental del futuro profesional en los diferentes Planes del Proceso Docente. Existe desactualización de los principales temas ambientales en los programas de las diferentes disciplinas y asignaturas de la carrera en cuestión que se imparten en del Centro Universitario del municipio La Sierpe; es limitada la reorientación de la educación ambiental en estos programas de disciplinas y asignaturas de la carrera, de igual manera la oferta de acciones de superación en estos contenidos para los profesores que laboran a tiempo parcial en el centro Universitario Municipal La Sierpe.

Sobre la base de lo anteriormente planteado el objetivo del presente trabajo se centra en reflexionar desde el punto de vista teórico acerca de la superación de los docentes para el tratamiento a la dimensión ambiental para el desarrollo sostenible.

\section{Revisión de literatura}

En el proceso de perfeccionamiento educacional cubano que, con carácter continuo, tiene lugar en el país, se ha venido madurando una nueva visión acerca de la educación ambiental, la cual debe ser un patrimonio del trabajo docente-educativo en el plano interdisciplinario y evitar la exclusividad de este tipo de labor dentro de las asignaturas correspondientes al campo de las ciencias naturales.

Un momento trascedente de este proceso de institucionalización de la gestión ambiental en Cuba fue en 1981, con la aprobación de la Ley 33 "De la Protección del Medio Ambiente y del Uso Racional de los Recursos Naturales". 
En Cuba se considera la educación ambiental como un proceso continuo y permanente que constituye una dimensión de la educación integral de todos los ciudadanos. Es por ello que lograr la elevación sostenida de los niveles de conocimientos en esta importante materia va a depender en gran medida de la organización, coherencia y capacidad institucional de los sistemas educativos en que se desarrolle la educación ambiental, para alcanzar su plena integración con una activa labor de todas las instituciones (docentes, culturales, científicas, comunitarias) orientadas a ese fin.

En consecuencia sobre el concepto de educación ambiental, la autora se acoge a la definición que aparece en la Ley No. 81 del Medio Ambiente, donde se aborda la educación ambiental como proceso continuo y permanente, que constituye una dimensión de la educación integral de todos los ciudadanos, orientada a que en la adquisición de conocimientos, desarrollo de hábitos, habilidades, capacidades y actitudes y en la formación de valores, se armonicen las relaciones entre los seres humanos y de ellos con el resto de la sociedad y la naturaleza, para propiciar la orientación de los procesos económicos, sociales y culturales hacia el desarrollo sostenible. (Ley 81 de Medio Ambiente, 1997, p. 13).

En correspondencia con este concepto, el profesional de la carrera Gestión Sociocultural para el Desarrollo mantiene relación con la naturaleza, puesto que, a lo largo de la historia, elementos del medio ambiente y los fenómenos o problemas que en él ocurren han sido fuente de inspiración literaria y artística cuyas expresiones, tienen relación con el sistema social de cada civilización y han rebasado las fronteras de estas y perdurado hasta los tiempos actuales.

En los primeros momentos del desarrollo humano, los hombres primitivos se sintieron parte de la naturaleza e inmersos en ella, dependientes de sus fuerzas cósmicas. La relación de estos con su entorno inmediato estuvo presente desde sus orígenes (Versón, R., 1984: 12). La interacción de estos con la naturaleza se mantuvo vigente en el desarrollo de todas sus actividades, ya con indicios de la presencia de elementos estéticos como: el sentido de la forma, el volumen y el color, el acatamiento de determinadas normas en las representaciones animales, humanas o simbólicas, entre otros.

Las literaturas antiguas orientales se apoyan en una rica tradición oral de mitos y leyendas, y el culto del hombre a la naturaleza deificada. En tal sentido, la cultura egipcia muestra la sensualidad y la belleza femenina acompañada por elementos propios de la naturaleza para resaltar su hermosura.

Asimismo, la hebrea exhibe en la Biblia, una fuente de placer estético muy vinculada a los elementos naturales. La belleza de las descripciones de la naturaleza y el propio mundo interior del individuo asombran por su capacidad de sintetizar a través de un símbolo natural, la belleza contenida en un rostro, cabello u otro elemento corporal. 


\section{EDUCACIÓN}

La literatura de la India presenta a un hombre en estrecha relación con la naturaleza, la que fue objeto de admiración, contemplación y refugio.

Más adelante en el caso de la cultura griega, la naturaleza recibió tratamiento artístico, sobre todo la humana. En su literatura se percibe en la concepción del héroe griego, casi perfecto física y psicológicamente, ubicado en espacios naturales que completan su caracterización. Esta, en su período, clásico tuvo al hombre como objeto esencial, pero en este caso no tan vinculado al elemento natural que sí se percibe en los mitos y leyendas.

La etapa medieval (siglo $\mathrm{V}$ hasta el siglo XV, aproximadamente), muestra una naturaleza desnaturalizada en la que el hombre es su presa. En el Prerrenacimiento y el Renacimiento (siglos XIV-XVI), el hombre como parte del medio fue centro y a la vez objeto creativo. Desde esta literatura se exalta la naturaleza humana. Según los textos el hombre se implica emocionalmente con la naturaleza.

En el siglo XVIII, hubo escritores que expresaron la poesía de amor; pero, sin alcanzar armonía con la naturaleza. Seguidamente en el período romántico, muestran una reacción contra el cosmopolitismo literario del siglo anterior. La literatura se hace más nacional, más diferenciada según los países, siente una mayor curiosidad por todos los aspectos externos de la vida, es más pintoresca, más llena de colorido, acentúa las diferencias entre las épocas y los lugares; da una gran importancia al detalle concreto, al color histórico o local.

En el referido período romántico, la naturaleza exterior ocupa un lugar importante; desde los ambientes exóticos y salvajes hasta los más simples horizontes rústicos. Casi todos los románticos evocan con una apasionada angustia los grandes problemas del mundo y del destino; manifiestan tendencias humanitarias y un interés nuevo por los problemas sociales. La naturaleza constituyó marco ideal para la expresión de sentimientos, representados de una manera armónica en relación con ella.

La literatura realista (finales del siglo XIX) muestra espacios inhóspitos a los que el ser humano se enfrenta. Recrea los sentimientos humanos en toda su extensión; desde los más nobles, hasta los más miserables, la depauperación de una sociedad llena de vicios, envidias y rencores. El Naturalismo como expresión máxima de esta tendencia, presenta al medio y al ser humano de manera cruda, en su perversidad, en su podredumbre, mostrando sus miserias, que lo llevan hacia una lucha con otros y consigo mismo.

Los movimientos artístico-literarios que se sucedieron desde los últimos años del siglo XIX hasta mediados del XX, con estructuras ideo estéticas diferentes, destruyen la imagen del mundo concebida hasta entonces y conforman el lenguaje de la cultura de la época, permeado por acontecimientos trascendentales como la Revolución 
Industrial que desarrolla en el individuo una manera de pensar diferente con respecto a la naturaleza, que se contamina con la aparición de las chimeneas de las grandes industrias. Ello repercute notablemente en la literatura al incorporar como motivos de creación elementos representativos de estos cambios (máquinas, gases).

El arte de vanguardia (primeras décadas del siglo XX, aproximadamente), refleja la crisis espiritual del hombre, y representa los problemas de este como parte misma de la naturaleza. Ella fue representada de manera fragmentada, devastada, destruida; es el propio lector-espectador quien la construye y la integra para poder apreciarla en toda su magnitud. En la literatura posmoderna se hace una revalorización de la naturaleza y la defensa del medio ambiente se mezcla con la compulsión al consumo. Hay una constante preocupación respecto a los grandes desastres y al fin del mundo y defiende la hibridación, la cultura popular, el descentramiento de la autoridad intelectual y científica.

La literatura constituye un medio apropiado para que, desde su apreciación, el individuo establezca las lógicas relaciones con el medio ambiente en un sentido amplio. Muchas creaciones literarias lo muestran como fondo o como un elemento activo, que no solo delimita el espacio, sino que ofrece información sobre personajes, sucesos, entre otros.

Desde esta perspectiva se hace contemporánea la conveniencia de evaluar la necesidad de deslindar los vínculos que pudieran existir entre la creación artística y las percepciones ambientales. En tal sentido, la ecocrítica literaria deviene herramienta que apoya esta intención docente, de manera que se cambien modelos profesionales en este sentido y se descubra la dimensión ambiental que pudiera surgir en el proceso de análisis de textos literarios.

La GSCD en el proceso la enseñanza-aprendizaje favorece el desarrollo de la sensibilidad en relación con el entorno y a la realización de valoraciones críticas con respecto a este. Esta beneficia el progreso de la conciencia sobre la gravedad de los daños ocasionados al medio ambiente y de una actitud en la que se manifieste una percepción de los valores naturales como partes integrantes de la cultura de cualquier nación, lo cual expresa la aprehensión de una relación diferente entre literatura y naturaleza.

Como parte de la GSCD es necesario el conocimiento de los problemas ambientales que son diversos y abarcan diferentes dimensiones espaciales. En Cuba, según se expone en la Estrategia Ambiental Nacional (EAN) 2017-2020, son de la planificación estratégica del Ministerio de Educación Superior, entre otros, el carácter sostenible del desarrollo, derecho al disfrute de un medioambiente sano y deber ciudadano con su protección, carácter educativo del trabajo ambiental y la planificación eficiente de 
mecanismos económico-financieros (Citma: EAN, 2017-2020). Ellos son asumidos en el contexto de la presente investigación.

\section{Metodología}

El estudio se desarrolló en el primer semestre del curso 2019-2020, en el Centro Universitario del municipio La Sierpe, Cuba. Para ello se tomó una muestra no probabilística de tipo intencional de 7 profesionales que laboran en la carrera Gestión Sociocultural para el Desarrollo, en la que se aplicaron como respuesta a la problemática declarada talleres de superación profesional en función de la educación ambiental de estos para el perfeccionamiento de su desempeño profesional.

Como rasgos que permitan la referencia empírica de la variable dependiente (talleres de superación) se determinan como indicadores los siguientes:

1. Nivel de conocimiento de los conceptos básicos de la educación ambiental.

2. Nivel de dominio de las exigencias didácticas para planificar, orientar y controlar el tratamiento a la educación ambiental desde los procesos de la Educación Superior.

3. Nivel en que logra la adecuada concepción del tratamiento a la educación ambiental desde los procesos de la Educación Superior.

4. Nivel de aplicación de la educación ambiental desde los procesos de la Educación Superior

La comprobación realizada en función de constatar el nivel de preparación de los docentes sometidos a condiciones experimentales corrobora limitaciones en cada uno de los indicadores declarados, confirmando la necesidad de buscar alternativas de solución, que en el caso nuestro se consideraron talleres de superación como parte de la superación profesional del profesor universitario.

\section{Resultados y discusión}

En correspondencia con la necesidad planteada se diseñaron se consideró como elemento novedoso de los talleres, desde un accionar metodológico, la fusión del rol participativo de los docentes, la autoevaluación como mecanismo para orientar la transformación de los sujetos y la utilización de dinámicas grupales como características fundamentales que dinamizan el cambio esperado.

Se considera, además, cuando se afirma que la superación profesional, debe desarrollarse a partir de un aprendizaje cooperativo con el objetivo de que todos aprendan los contenidos hasta el máximo de sus posibilidades; desde la responsabilidad 
individual de conseguir las metas individuales y comunes que se les ha asignado y desde la participación igualitaria.

Para la presente investigación, se asumirá la formación continua del profesional desde las actividades formativas, conferencias, talleres y cursos de postgrado desde la formación en el Derecho Ambiental, en el nivel organizativo de los posgrados, a través de la superación profesional, como estructura de la educación de posgrado.

La autora pudo corroborar mediante el análisis del plan de estudio, que la educación ambiental tiene un significado particular en la carrera Gestión Sociocultural para el Desarrollo por lo que resulta necesario la implementación de los talleres que contribuya a elevar el nivel de preparación de los docentes y por ende a la educación ambiental de los estudiantes para el ejercicio de la profesión.

\section{Conclusiones}

1. La educación ambiental tiene sus fundamentos teórico-metodológicos en la génesis y evolución de este proceso; en la política actual y en los estudios de las ciencias pedagógicas cubanas en relación con la educación ambiental en la formación inicial de los profesionales, en general; y de la educación superior en particular; en la necesidad de la comprensión y tratamiento de los problemas ambientales desde el enfoque integrador y de su contextualización en el entorno de la institución educativa; así como en la concepción de su tratamiento desde el proceso pedagógico.

2. Los elementos teóricos consultados permiten aseverar que la superación postgraduada constituye una vía para garantizar la preparación del docente para el tratamiento a la dimensión ambiental para el desarrollo sostenible.

\section{Lista de referencias}

Castro, F (1992). Discurso pronunciado en la Cumbre de la Tierra sobre Medio Ambiente y Desarrollo de Río de Janeiro. Editorial Granma.

Declaración de Río de Janeiro. (1992). Brasil: Recuperado de www.ecured.cu/index. php/Cumbre-de-la-Tierra-de-Río-de-Janeiro

Ley \# 33 de Protección del Medio ambiente y del Uso Racional de los Recursos Naturales. (1981). La Habana.

Ley \#81 del Medio Ambiente. (1997). La Habana. 


\section{EDUCACIÓN}

Ministerio de Ciencia Tecnología y Medio Ambiente (CITMA) (1997). Estrategia Nacional de Educación Ambiental. Centro de Información, Gestión y Educación Ambiental. Agencia de Medio Ambiente. Recuperado de: http:// www. cuba. $\mathrm{cu} /$. Autor.

Ministerio de Educación Superior (2004). Resolución ministerial 132. La Habana, Cuba. 